\section{The quality of online information regarding dental implants}

\author{
S. Ali, ${ }_{1}$ K. Woodmason ${ }^{2}$ and N. Patel ${ }^{* 3}$
}

IN BRIEF
- Enables the reader to understand how
patients use online information to make
informed choices.
Explains how the Internet has the
potential to dramatically change the
doctor-patient relationship in that it offers
an opportunity for patients to increase
their involvement in their healthcare
decision-making process.
- Highlights the GDC regulations on ethical
advertising.

\begin{abstract}
Aims and objectives To analyse the quality of online information available to patients regarding dental implants. Design Cross sectional survey. Setting The websites analysed were UK based, owned by private practices and NHS secondary and tertiary care services. Information was collated in November 2013. Methods UK-based websites were analysed using UK based search engines. Outcome measures Websites were analysed based on content and reliability. Information regarding the speciality of authors and accreditation/affiliation to professional groups/medical institutions was also collated. Results Overall, website content quality was low, with 63\% of sites averaging below 7/14 for their mean summed website content scores, and 67\% of sites averaging below 8/16 for their mean reliability scores. 86.7\% were accredited by a recognised national/international dental/surgical body but only $26.7 \%$ were affiliated to a professional group/medical institution. The authors were mainly dentists (73.3\%). Conclusions These findings suggest that the online information regarding implant treatment is generally of low quality and many aspects such as long term outcomes and complications are overlooked. There is a need for the improvement of the quality of online information available to patients in order to make the best use of this tool in helping patients to make informed choices about their dental care. The Internet has the potential to dramatically change the clinician-patient relationship. Moreover, in light of the guidelines produced by the General Dental Council (GDC) in 2012 on the principles of ethical advertising, GDC registrants run the risk of fitness to practise proceedings and medico-legal challenges if the website content has potential to mislead patients.
\end{abstract}

\section{INTRODUCTION}

Dental implantology has enjoyed extensive research and developments over recent years. This has led to an increasing number of implant designs, loading protocols and prosthetic options. The current literature has reported the success rates of dental implants to be as high as $93-98 \%,,^{1-3}$ with the associated restorations having a lifespan of $10-15$ years. ${ }^{4}$ With the increase in availability, dental implants are becoming a more desirable treatment option to patients for the replacement of missing teeth.

While every effort is taken to deliver information regarding procedures, risks and benefits to patients during implant consultations,

${ }^{1}$ Academic Clinical Fellow in Special Care Dentistry, Bristol Dental Hospital, Lower Maudlin Street, Bristol, BS1 2LY; ${ }^{2}$ Dental Core Trainee, University Dental Hospital of Manchester, Higher Cambridge Street, Manchester, M15 6FH; ${ }^{3}$ Academic Clinical Fellow in Oral Surgery, The University of Manchester, School of Dentistry, Coupland 3 Building, Coupland Street, Manchester, M13 9PL

${ }^{*}$ Correspondence to: Dr Neil Patel

Email: neil.patel@cmft.nhs.uk

Onlline article number E16

Refereed Paper - accepted 2 September 2014

DOI: 10.1038/sj.bdj.2014.979

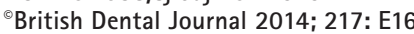

very often this information is not absorbed and retained. Estimates suggest that 40-80\% of material delivered during a consultation cannot later be recalled. ${ }^{5}$ As a result patients are frequently encouraged to seek further information, and many do so via the World Wide Web., ${ }^{6,7}$ The Internet is a major source of material relating to healthcare, however, the quality of the information that is accessible is variable, ${ }^{8-10}$ with varying levels of supporting evidence. Unreliable, inaccurate or very basic information may lead to inappropriate patient perceptions, unrealistic expectations and poor decision-making when considering treatment options. Furthermore this can open clinicians to suggestions of malpractice and non-conformance to standards that are expected from a dental professional, ${ }^{11}$ with further implications regarding the validity of any consent gained for the procedure to be undertaken.

When searching the Internet most patients will utilise a search engine such as Google or Yahoo when seeking information. The search results that are generated on such sites are based on page rank algorithms rather than the quality of the information contained within them. Evidence suggests that individuals tend to read through the information contained within the first 30 search results, meaning that better quality materials may be overlooked. ${ }^{12}$

Many tools have been developed to examine the quality of information available to patients. The DISCERN tool was originally designed to examine the quality of patient information leaflets, however it is now widely applied when examining websites with patient information contained within them. It has been validated and is robust when assessing the reliability and quality of patient information. ${ }^{13,14}$ It is, however, limited in that there is no assessment of the accessibility or ease of navigation of websites. ${ }^{13}$

A number of studies have examined the quality of information that is available to patients within the field of medicine. However, it has been previously noted that there are very few studies that examine the information that is available for procedures within oral and maxillofacial surgery. ${ }^{8}$ With public interest and the demand for dental implants rising, and with an increasing number of clinicians offering dental implants as a treatment option, it is imperative that 
patients have reliable, good quality sources that offer further information. Therefore, the aim of this study was to examine the quality of information available to patients on the Internet regarding dental implant treatment.

\section{METHODS}

It was the authors' intentions to replicate the search strategy of a layperson for gaining additional information about dental implants. The UK versions of Google and Yahoo have the highest share for all Internet searches carried out in the UK. ${ }^{15}$ Consequently these search engines were used for this study. The search terms 'dental implant' or 'dental implants' were input into the search bar and the first 30 websites were chosen for examination as it was assumed a lay member of the public would not look further than the first three pages of search results. We included all (UK and international) websites containing information directed towards patients about dental implant placement. Websites that required a log-in/password, were inaccessible, duplicated or provided a marketing-based forwarding link to another website were excluded.

The 30 websites were scrutinised according to the DISCERN tool categories: accessibility, target audience, provision of reference materials, owner of site, produced by a professional association/group, professional status of author and accreditation of site.

DISCERN categories were scored by two authors (KW, NP) from 0 to 2 based on whether the tool criteria were addressed and deemed by the authors to be in accordance with current accepted evidence based UK practice (score 2), addressed but not in accordance (1) or not addressed (0).

Websites received a total score after summation of scores from all the categories.

\section{RESULTS}

Table 1 shows the basic website characteristics of the 30 websites reviewed. Of the 30 websites reviewed $86.7 \%$ were accredited websites (accredited by a recognised national/international dental or surgical body) but only $26.7 \%$ were produced by professional group/body. The authors were mainly dentists (73.3\%) or unspecified (20\%) (Fig. 1), and the commonest website owners were general dental practitioners (70\%) followed by oral surgeons (13\%) (Fig. 2).

Website reliability scores are shown in Table 2, and website content scores are shown in Table 3 . The mean total website reliability score was 5.4 (range 0-16), the mean total website content score that is, the quality of information on various aspects of treatment was 4.9 (range 0-14). Within the website content scores 'benefits of treatment' and 'procedure' details had the highest

\begin{tabular}{|c|c|c|}
\hline Website feature & $\mathrm{n}$ & $\%$ \\
\hline \multicolumn{3}{|l|}{ Accessible } \\
\hline Yes & 30 & 100 \\
\hline No & 0 & 0 \\
\hline \multicolumn{3}{|l|}{ Site origin } \\
\hline UK & 28 & 93.33 \\
\hline US & 1 & 0.03 \\
\hline EU & 1 & 0.03 \\
\hline \multicolumn{3}{|l|}{ Accredited } \\
\hline Yes & 26 & 86.67 \\
\hline No & 4 & 13.33 \\
\hline \multicolumn{3}{|l|}{ Affiliation } \\
\hline Yes & 8 & 26.67 \\
\hline No & 22 & 73.33 \\
\hline \multicolumn{3}{|l|}{ Website owner } \\
\hline GDP & 21 & 70 \\
\hline Oral surgeon & 4 & 13.3 \\
\hline University & 1 & 0.03 \\
\hline Association & 2 & 6.70 \\
\hline Web based & 2 & 6.70 \\
\hline Journal & 0 & 0 \\
\hline \multicolumn{3}{|l|}{ Author } \\
\hline Dentist & 22 & 73.3 \\
\hline Oral surgeon & 2 & 6.7 \\
\hline Maxillofacial surgeon & 0 & 0 \\
\hline Craniofacial surgeon & 0 & 0 \\
\hline Layperson & 0 & 0 \\
\hline Unspecified & 6 & 20 \\
\hline
\end{tabular}

mean scores of 1 , and 'other options' and 'long term outcomes' had the lowest website scores (0.4 and 0.5). Within the website reliability scores, the category with the highest mean score was 'relevance', and the category with the lowest mean score was 'information unbiased' (mean score 0.6).

The mean total website content scores for websites which were authored by dentists $(\mathrm{n}=22$, mean $=4.78)$ was significantly lower than the mean website content scores for websites whose authors were unspecified $(\mathrm{n}=6$, mean $=8)(\mathrm{p}=0.011)$. The mean total website reliability score was also significantly lower for websites whose authors were dentists $(n=22$, mean $=4.1)$ compared to those websites where the authors were unspecified $(n=6$, mean $=7.8)(p=0.025)$.

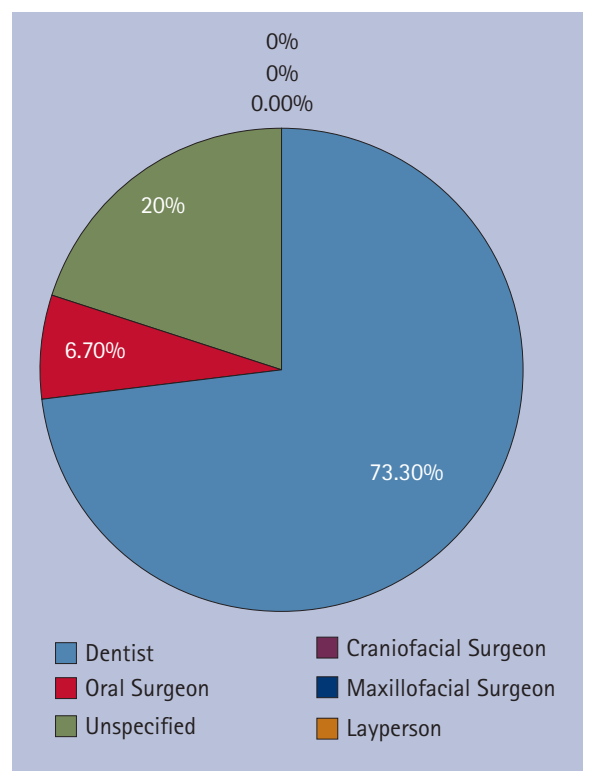

Fig. 1 Distribution of website authors, $\mathbf{n}=\mathbf{3 0}$

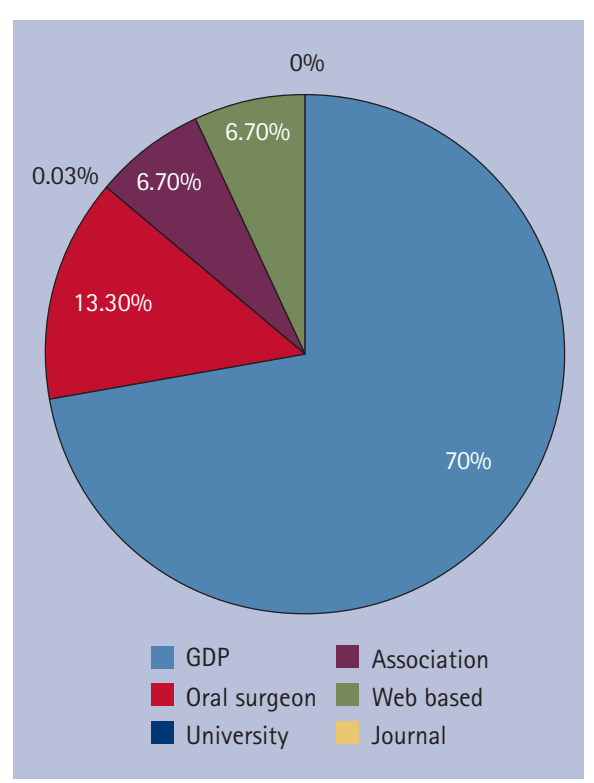

Fig. 2 Distribution of website owners, $n=30$

\section{DISCUSSION}

Patients are increasingly using the Internet to gain more information on diagnosis and treatment options. A survey in 2001 in the United States survey showed that 52 million adults have used the World Wide Web to obtain health or medical information. ${ }^{16}$ Access to large amounts of medical information is available through an estimated 20,000 to 100,000 health-related websites. ${ }^{17}$ The lack of regulation of these websites makes it important to assess both the quality of the information available as well as any important omissions. ${ }^{8}$ Studies of the quality and accuracy of health and medical information available on the Internet have shown that many sources provide inadequate information. Jayaratne et al. (2013) assessed the readability of patient-oriented online information on dental implants and found that 34 of 39 websites (87.18\%) were difficult to read. ${ }^{9}$ 


\section{Table 2 Mean website reliability scores}

Website reliability scores

\begin{tabular}{l|l|l}
\hline Reliability variable & Mean score & Range \\
\hline Aims clear? & 1.23 & $0-2$ \\
\hline Achieves aims? & 1.17 & $0-2$ \\
\hline Relevance & 1.27 & $0-2$ \\
\hline Sources clear? & 0.13 & $0-2$ \\
\hline Publication date of information used clear? & 0.17 & $0-2$ \\
\hline Information balanced/ unbiased? & 0.6 & $0-2$ \\
\hline Details for additional support/ information provided? & 0.73 & $0-2$ \\
\hline Average reliability score for 30 websites & 5.43 & $0-16$ \\
\hline
\end{tabular}

Table 3 Mean website content scores based on quality of information on various aspects of treatment

\begin{tabular}{|l|l|l|}
\hline \multicolumn{3}{|l}{ Website content scores (based on quality of information on various aspects of treatment) } \\
\hline Content variable & Mean score & Range \\
\hline Indications & 0.9 & $0-2$ \\
\hline Procedure & 1 & $0-2$ \\
\hline Benefits of treatment & 1.03 & $0-2$ \\
\hline Complications & 0.6 & $0-2$ \\
\hline Healing times & 0.5 & $0-2$ \\
\hline Long-term outcomes & 0.47 & $0-2$ \\
\hline Other options explained & 0.43 & $0-2$ \\
\hline Mean score for 30 websites reviewed & 4.93 & $0-14$ \\
\hline
\end{tabular}

The categories used in this study to assess website content (quality of information on treatment) and website reliability focus on essential basic information that a patient would require to understand what implant treatment entails. The website content scores were based on quality of information for parameters such as indications of treatment, details about the procedure, benefits and complications of the treatment, as well as long term outcomes and other options. The results of this study showed that most websites were authored by dentists, and although these websites authored by dentists scored highly in 'indication' and 'benefits of treatment', they had low scores for the 'complications' category, leading to low summed website content for these websites. The mean score for the 'complications' category for websites authored by dentists $(\mathrm{n}=22$, mean $=0.5$ ) was significantly lower than the mean content score for 'complications' category for websites written by unspecified authors $(n=6$, mean $=1.2)(p=0.031)$. This could be explained by the fact that the websites written by dentists were likely to be commercially motivated. These dentists may have been advertising their services through these sites, and perhaps did not want to draw attention to the complications or any potentially negative aspects of implant treatment.

The mean total website content score, that is, the quality of information on treatment, was only 4.9 out of 14 , with $63 \%$ of sites averaging below 7 out of 14 for their mean summed website content scores, and 67\% of sites averaging below 8 out 16 for their mean reliability scores. Forty percent of the websites scored 0 out of 2 for quality of information for the category 'indication' of treatment meaning that $40 \%$ of these implant websites didn't provide any information on the indication for implants. Similarly $60 \%$ of these website scored 0 out of 2 for the quality of information provided on 'complications' of treatment, a major omission for a website which patients may access to make informed decisions. Sixtythree percent of websites scored 0 out of 2 for quality of information provided on long term outcomes, which is vital information for patients undergoing surgery with associated morbidity and financial implications.

The information on websites can be a useful tool within the process of informed consent. One of the most relevant factors for patients deciding on implant treatment is the long term outcomes, as well as the advantages and disadvantages of alternative options. Levin et al. in 2013 carried out a systematic review of long-term tooth and implant survival rates. ${ }^{2}$ They concluded that survival rates do not exceed those of compromised but adequately treated and maintained teeth, supporting the notion that the decision to extract a tooth and place a dental implant should be made cautiously. Furthermore they explained that even when a tooth seems to be compromised and requires treatment to be maintained, implant treatment also might require additional surgical procedures that might pose some risks as well. ${ }^{19}$ Despite these well documented facts in a systematic review, the websites reviewed in this study had the lowest scores for the long term outcomes and explanation of other options.

In 2012, the GDC published guidelines on the principles of ethical advertising. ${ }^{20}$ The GDC recognise that advertising by dental professionals can be a source of information to help patients make informed treatment choices, and have provided specific guidance for GDC registrants when advertising services, particularly on websites. In particular they advise that statements or claims intended or likely to create an unjustified expectation about the results that can be achieved must be avoided, and that advertising that is false and has the potential to mislead patients is unprofessional, may lead to referral to fitness to practise proceedings and can be a criminal offence.

\section{CONCLUSION}

These findings suggest that the online information available to the public regarding implant treatment is generally of low quality and many aspects such as long term outcomes and complications are overlooked. Clinicians should be aware that patients may use online information as a source of health information, and should be able to recommend high quality accredited websites to patients and assist patients in evaluating the quality of this information. The Internet has the potential to dramatically change the doctor-patient relationship in that it offers an opportunity for patients to increase their knowledge, become more informed, and increase their involvement in their healthcare decision-making process. ${ }^{16}$ Moreover, GDC registrants run the risk of fitness to practise proceedings and medico-legal challenges if the website content has the potential to mislead patients, as explained in the GDC 2012 guidelines on ethical advertising. 
1. Papaspyridakos P, Mokti M, Chen C J, Benic G I, Gallucci G O, Chronopoulos V. Implant and prosthodontic survival rates with implant fixed complete dental prostheses in the edentulous mandible after at least 5 uears: a systematic review. Clin Implant Dent Relat Res 2013; doi: 10.1111/cid.12036 [Epub ahead of print].

2. Pjetursson B E, Thoma D, Jung R, Zwahlen M, Zembic A. A systematic review of the survival and complication rates of implant-supported fixed dental prostheses (FDPs) after a mean observation period of at least 5 years. Clin Oral Implants Res 2012; 23: 22-38.

3. Berglundh T, Persson L, Klinge B. A systematic review of the incidence of biological and technical complications in implant dentistry reported in prospective longitudinal studies of at least 5 years. $J$ Clin Periodontol 2002; 29 (Suppl 3): 197-212, 232-233.

4. Bozini T, Petridis H, Garefis K, Garefis P. A meta-analysis of prosthodontic complication rates of implantsupported fixed dental prostheses in edentulous patients after an observation period of at least 5 years. Int J Oral Maxillofac Implants 2011; 26: 304-318.

5. Kessels R P. Patients' memory for medical information. J R Soc Med 2003; 96: 219-222.

6. Murero M, D'Ancona G, Karamanoukian H. Use of the Internet by patients before and after cardiac surgery: a telephone survey. J Med Internet Res

\section{1; 3: E27.}

7. Fashner J, Drye S T. Internet availability and interest in patients at a family medicine residency clinic. Fam Med 2011; 43: 117-120.

8. Cobb R J, Scotton W J. The reliability of online information regarding orthognathic surgery available to the public. Oral Surg 2013; 6: 56-60.

9. Jayaratne Y S N, Anderson N K, Zwahlen R A. Readability of websites containing information on dental implants. Clin Oral Implants Res 2013 doi: 10.1111/clr.12285 [Epub ahead of print].

10. Sajid M S, Iftikhar M, Monteiro R S, Miles A F, Woods W G, Baig M K. Internet information on colorectal cancer: commercialization and lack of quality control. Colorectal Dis 2008; 10: 352-356.

11. Al-Bahrani A, Plusa S. The quality of patientorientated Internet information on colorectal cancer. Colorectal Dis 2004; 18: 323-326.

12. General Dental Council. Standards for the dental team. Available from: https://www.gdc-uk.org/ Dentalprofessionals/Standards/Documents/ Standards\%20for\%20the\%20Dental\%20Team.pdf 2013 (accessed 10 October 2013).

13. Yeung T M, D'Souza N D. Quality analysis of patient information on surgical treatment of haemorrhoids on the Internet. Ann R Coll Surg Eng/ 2013; 95: 341-344.
14. Charnock D, Shepperd S, Needham G, Gann R. DISCERN: an instrument for judging the quality of written consumer health information on treatment choices. J Epidemiol Community Health. 1999; 83: 105-111.

15. Search Engine Watch. Available at: https://searchenginewatch.com (accessed October 2014).

16. Diaz J A, Griffith R A, Ng J J, Reinert $S E$, Friedmann P D, Moulton A W. Patients' use of the Internet for medical information. J Gen Intern Med 2002; 17: 180-185.

17. Eysenbach G, Sa E R, Diepgen T L. Shopping around the Internet today and tomorrow: towards the millennium of cybermedicine. BMJ 1999; 319: 1294.

18. Sullivan T B, Anderson J T, Ahn U M, Ahn N U. Can Internet information on vertebroplasty be a reliable means of patient self-education? Clin Orthop Relat Res 2014; 472: 1597-1604.

19. Levin L, Halperin-Sternfeld M. Tooth preservation or implant placement: a systematic review of longterm tooth and implant survival rates. J Am Dent Assoc 2013; 144: 1119-1133.

20. General Dental Council. Principles of ethical advertising. Available at: http://www.gdc-uk.org/ dentalprofessionals/standards/documents/ethical\%20advertising\%20statement\%20jan\%202012. pdf (accessed October 2014). 